\title{
How Faculty Create Learning Environments for Diversity and Inclusion
}

\author{
Keonya C. Booker, PhD \\ Assistant Professor, Department of Teacher Education \\ College of Charleston \\ Gloria D. Campbell-Whatley, PhD \\ Associate Professor, College of Education \\ University of North Carolina at Charlotte
}

The demographics of college campuses are changing and necessitate faculty provide a safe and inclusive environment for learning. The purpose of this study was to examine how faculty establish a sense of belonging in their classrooms, using focus group methodology to explore

issues of power, privilege, and access at the postsecondary level. Faculty $(N=33)$

representing multiple identity groups discussed opportunities and challenges in effectively reaching diverse groups of students. Three thematic categories emerged illustrating how faculty prepare their courses for inclusive content, develop in-class instructional practices including methods regarding assessment, and believe in professional responsibility through persistent role modeling.

College campuses are more diverse now than ever (Museus, Yi, \& Saelua, 2017). The number of students from multicultural backgrounds continues to grow as opportunities abound for previously underrepresented groups to obtain a postsecondary education. While most would argue that a diverse learning environment is ideal and can bring benefit to the larger campus community, some faculty still struggle with how to create a feeling of inclusion in the classroom setting. This hesitation is particularly salient as tensions rise across the country in the wake of recent socio-political events (Hesse, 2017). In everyday course interactions, faculty and students have to navigate potential landmines that highlight issues of power, privilege, and access in a post-racial environment (Niehaus \& Williams, 2016). It can be a daunting task for those professors not equipped with the instructional techniques and strategies to provide a psychologically safe environment for their students.

For years there has been an emphasis on increasing diversity in college settings, and there is a growing need to ensure that the inclusion of disparate voices is heard (Cuyjet, Linden, Howard-Hamilton, \& Cooper, 2016). Research indicates that retention is predicated on numerous social, motivational, and academic factors (Tinto, 1993), not the least of which is how closely connected students feel to their professors and peers in the classroom setting. The quality of faculty-student relationships is at the cornerstone of inclusion (Kim \& Sax, 2017). When students feel their beliefs and backgrounds are respected and valued, they report a stronger connection to their college environment (Wilson \& Gore, 2013). To this end, the purpose of this study was to explore how faculty create an inclusive environment in the college classroom setting.

\section{Theoretical Framework and Literature Review}

Maslow's theory (1943) of human motivation and self-actualization provides a useful premise for the importance of establishing a sense of community amongst 
students. Maslow contended that all humans have basic needs that must be met prior to achieving more lofty and advanced goals. In this hierarchy of needs, Maslow argued one must first feel the psychological needs of love and belongingness before they can ascend to higher planes on the pyramid, such as mastery and achievement. Specifically, before students can be expected to demonstrate motivation and engagement, they need to feel a sense that they belong. As humans we are tribal and depend on those in our surroundings to provide support and encouragement (McMillan \& Chavis, 1986; Strayhorn, 2012). In the college classroom this is best described as sense of school belongingness.

Typically studied in K-12 settings, school belonging is a psychological construct that emphasizes valuing, connection, and caring (Goodenow, 1993; Osterman, 2000). In collegiate settings, school belonging has been studied in relation to student retention (Hausmann, Schofield, \& Woods, 2007), campus climate (Johnson, 2012), psychological adjustment (Schochet \& Smith, 2014), and academic engagement (Zumbrunn, McKim, Buhs, \& Hawley, 2014). Belongingness is a multifaceted and complex state of being that is heavily influenced by both internal and external factors. A significant external factor is the degree to which instructors establish a psychologically secure and safe space for learning to take place. When students feel disrespected, unwelcomed, or fearful, learning is minimized. Conversely, when classroom dynamics are positive, inclusive, and engaging, learning can flourish optimally (Murphy \& Zirkel, 2015).

A consistent metric of student belongingness is how connected students feel to their instructors and peers (Finn \& Zimmer, 2012). Fredricks, Blumenthal, and Paris (2004) assert that belongingness is an affective state of engagement, one that is heavily influenced by how students feel about themselves and others in the classroom (Kay, Summers, \& Svinicki, 2011). While behavioral and cognitive engagement is important,

Belongingness is a multifaceted and complex state of being that is heavily influenced by both internal and external factors. the socio-emotional relationships students develop are vital as well. When students feel bonded with the university through positive experiences with classmates and faculty members, their feelings of self-worth and perceived competence increase (Pittman \& Richmond, 2007). This heightened sense of belonging then increases the likelihood of persistence to degree (Pascarella, Pierson, Wolniak, \& Terenzini, 2004).

The research is very clear about what college students want from their professors: accessibility (Case, 2013), warmth (Morrow \& Ackerman, 2012), organizational detail (Weaver \& Qi, 2005), and compassion (O'Keeffe, 2013) are just a few of the characteristics mentioned in the literature. Students want to know that they can reach out to faculty when they need support or encouragement (Booker, 2016). They also expect faculty to be sensitive to their feelings and maintain a respectful environment that is not hindered by disrespect and antagonism (Sidelinger, Bolen, Frisby, \& McMullen, 2011). Part of this process requires faculty to be aware of and sensitive to how multicultural groups of students experience a common learning environment. Faculty who are committed to culturally relevant andragogy know how to employ cultural scaffolding as a way to help students use "their own culture and 
experiences to expand their intellectual horizons and academic achievement" (Gay, 2002, p.109).

While these qualities appear rather straightforward in their implementation, a considerable number of faculty nevertheless have expressed concern over their abilities to encourage progressively inclusive classroom environments (Funge, 2011; Valentine, Prentice, Torres, \& Arellano, 2012). When attending to multiple perspectives and backgrounds, some professors do not feel equipped to construct learning environments that support the participation and engagement of students from diverse backgrounds. Of particular concern is how to integrate multicultural perspectives into course content without it appearing like an "add-on" component. Faculty have personal conceptions of community that are sometimes unable to be translated into the classroom setting, especially as it relates to instructional practices such as rigorously assessing students' reflective assignments, selecting student partners for group work with an eye focused on demographic differences, etc. Professors have to balance divergent perspectives without judgment, favoritism, or preference. Faculty also find that some students are resistant to discussing "hard topics," such as sexism and racism, which can leave a significant void in students' content knowledge of certain academic disciplines without faculty willing and able to guide learning in those provocative areas of discourse (McHatton, Keller, Shircliffe, \& Zalaquett, 2009).

In this study, we presented the challenges and opportunities faculty experience when establishing an inclusive environment. Our goal was to add to the literature on culturally relevant andragogy and multicultural course change at the postsecondary level. The research questions in this study were:

1. How do faculty define inclusion?

2. What, if any, instructional practices do faculty incorporate to address inclusive practices?

3. What concerns do faculty have regarding how to create an inclusive instructional environment?

\section{Context and Participants}

\section{Methodology}

This study took place at a mid-size university in the Southeastern United States. The institution enrolls 18,000 undergraduate and graduate students with over 150 majors. Almost all of the 930 full-time faculty members have professional or terminal degrees. Students of color account for $15 \%$ of the population. The five-year graduation rate is $71 \%$. This qualitative study was a part of a larger university-wide survey project. Faculty who completed a survey on diversity and inclusion were invited to participate in focus group interviews. A total of 33 faculty members participated in this sub-study. Twenty females and 13 males from various departments across campus agreed to be involved with the project. Academic affiliations included Arts and Sciences, Health Sciences, College of Education, College of Business, and Fine and Applied Arts. Fifty-five percent of the sample were tenured and $45 \%$ were nontenured (tenure-track and clinical instructional) faculty. Instructional course loads ranged from small, upper-level seminars to large undergraduate lecture sections. 
Twenty-five faculty members $(78 \%)$ classified themselves as Caucasian/White. The largest age group represented was 30-49 years old (53\%); those aged 50 or older made up $37 \%$ of the sample, with the smallest number being faculty members aged 20-29.

\section{Data Collection}

Six focus groups were conducted over the course of the spring semester. Each focus group connected faculty from similar backgrounds; for example, there was a focus group for female faculty only. The reason to separate faculty into demographic categories was to elicit honest and candid responses that may not have been as easily obtained in a more heterogeneous group (Onwuegbuzie, Dickinson, Leech, \& Zoran, 2009). A structured interview protocol was developed that asked specific questions about the ways in which each group of faculty participants shaped their courses to be inclusive and represent various facets of diversity. Sample questions included: What do you do in your courses to help students realize that inclusion plays an important role in the subject matter that you are teaching (i.e., assessment methods, examinations, student projects, journals, self-assessment, etc.)? What type of challenges and concerns, if any, have you experienced addressing inclusion within your courses? Each focus group interview lasted from 45 to 75 minutes. All participants agreed to be audio-recorded during the interviews. To enhance the analytical process, field notes were taken to add to the verbatim transcription.

\section{Data Analysis}

An inductive process was chosen to analyze the data. According to Thomas (2006), "Inductive approaches are intended to aid an understanding of meaning in complex data through the development of summary themes or categories from the raw data" (p. 3). The first step in analysis was to clean the data; this meant all interview data recordings were transcribed for accuracy during the analytical process. From there, we read over all transcriptions for common language used by the participants in response to the questions presented (Creswell \& Poth, 2017). In the third step, we generated categories based on the information gathered during the focus group. We had to make judgments about how to prioritize certain data points (Thomas, 2006). The final step was to reduce and refine the thematic categories into core ideas that illustrated the research objectives.

\section{Trustworthiness}

This project was fully vetted and granted approval by the University Institutional Review Board. All participants were made aware of consent procedures and ethical guidelines were followed. Trustworthiness was evaluated in two ways. First, a stakeholder check was conducted by encouraging faculty input into the data collected and to correct any misinterpretations. A second approach was to achieve a consistency check (Thomas, 2006, p. 7) between the members of the research team. Each researcher was given parts of the raw interview data and tasked with confirming the categorical conclusions of the others. This process involved detailed readings of the interview data, the codes developed, and the thematic categories established. 


\section{Findings}

In response to the first research question, faculty used many common terms and phrases to define inclusion such as respect, welcoming, diversity, openmindedness, and safety. These terms were used to describe both states of mind as well as deliberate actions faculty would take when working with diverse populations of students. Overall, three findings emerged from the interview data for research questions two and three: the importance of adequate course preparation, use of culturally relevant in-class practices, and a strong belief in role modeling and professional responsibility. All three themes are presented with illustrative quotations to underscore the voice of the faculty participants. The findings are also organized in a chronological way to represent faculty preparing for their courses, presenting the course content, assessing student learning and then reflecting on their own professionalism within the discipline.

\section{Adequate Course Preparation}

A number of faculty discussed the importance of beginning the course with explicit statements about the diverse nature of topics discussed in the class and how there was an expectation of respect and consideration for all perspectives and experiences. Faculty expressed the need to be clear with students from the beginning so as to minimize surprise or confusion. For many it was prudent to include these philosophies in the syllabus as a way to ensure students were aware of how class sessions would be conducted and the emphasis that would be placed on inclusive learning goals. The following are quotations from three different participants gathered by the audio-recordings from the focus group:

I think if you put it [inclusive statement] in the syllabus as our contract with the student...if you're pretty straightforward in saying these [diverse perspectives] are the items we're going to address...you're making that contract and kind of reinforcing the idea that this is a valued item... whether the students pay attention to those contracts is a different story...but that's how we view the syllabus...this is what I'm going to tell you, this is what's going to happen in this class...

I put in my syllabus readings about implicit bias and stereotype threat and how that works to structure fields...how that [stereotype threat] works in people being perceived as leaders...people being perceived as good teachers...I just make it [inclusive content] thematic...

I put a statement in my syllabus that says "In this course you will encounter texts that may have ideas that you don't agree with and I don't expect you to agree with them but you need to be familiar with them"...basically for my protection and for the protection of other students who may, you know, get attacked and want to have a policy to refer to that says "no, this is okay"...the syllabus is the contract for this class... 
In addition to contractual statements in the syllabus, faculty also turned a significant portion of responsibility back onto students to share in the experience of creating an inclusive environment. As previously mentioned (Hausmann et al., 2007; Murphy \& Zirkel, 2015), peer interactions are vital to maintaining a positive learning environment. Faculty mentioned how they would be intentional with providing prompts for large group discussions, small group work, and overall classroom interpersonal dynamics. This statement from a female professor spoke to the importance of emphasizing her expectations for how all participants are responsible for contributing positivity and support in the classroom setting:

I ask the students to help me create a climate of a welcoming environment where I say, "all persons of [all] races, classes, genders, sexualities, religions are respected"...I say that harassing will not be tolerated...

Usually when we're going to have a group discussion I just start it with "all opinions are valid and allowed to be said whether you agree or disagree"...that it's a time to develop your opinions by discussion and so they're told that everyone gets to speak regardless of whether they're saying what I say or something totally different...

\section{In-Class Practices: Language and Intentionality}

In the aforementioned thematic category, faculty discussed the importance of setting the scene early for students to feel a sense of connection and ease within the classroom. Another theme that emerged from the data related to specific instructional practices faculty would use to emphasize the way that students should express themselves and treat others during class meetings. Civility in speech is an issue that many college and universities face (Popovics, 2014). Faculty expressed a willingness to support students in navigating the sometimes difficult terrain of maintaining amicable conversations during class discussions and debates. These two education faculty members imparted steps they took to focus on invitational language in the classroom:

I teach inclusion and diversity in all of my classes...I teach educators...a big chunk of my classes include diversity as content but I also start out the class talking about gender pronouns and trying to use them and make sure that I'm including everyone's...so content wise it's in my classes but we also work on how to engage each other in discussion using appropriate language...

We do have one course that is entitled Diversity and Inclusion...these are graduate students but they' re going to be working with college and university students across the nation...so, in that particular course, we have them sign an affirmation statement and the reason being is to open up dialogue because even at that level they're not always sure about what it is that they value and, more importantly, they might be too sure...for instance, where I see the rub is where there might be some students that are pretty religious and they're struggling with trying to balance religion with their views on say homophobia or whatever...so it's more of a way to open up dialogue...that's what we're trying to get at...sustained dialogue that we have on campus so that students are not turning each other off but communicating in a civil way... 
Faculty also stressed how providing relevant examples to students of multicultural perspectives allowed for a more inclusive learning environment. Students need to see themselves in the relevance of the content area (Bain, 2004). Faculty who were committed to establishing a sense of community and inclusion were highly attuned to this practice of highlighting those outside the dominant norm. While each of the following three faculty members represented very different academic disciplines, all of them were cognizant of intentionally incorporating diverse perspectives and examples into their instruction:

I teach in a STEM field that, I think, historically has a pretty terrible track record of inclusion and equity...I try to teach the historical context of the major scientific discoveries we talk about in class...usually on the first day of class...but certainly in the first few weeks I make it clear that there's a reason we're only talking about old White guys...because the field has a history of racism and sexism and I usually try to say pretty explicitly that's an ongoing thing and not a historical artifact...

I teach art and when I'm showing examples of work by different artists I make sure that I'm not just showing, you know, a White male dominated example of artwork...actually I try and avoid showing White men's work as much as possible...

I'm an anthropologist and so different cultures and diversities are subject matter and I'm an archaeologist, specifically, so in my classes...kind of along the lines of making sure that not just White guy art is shown...I try and assign readings that are not just by White guy archaeologists but also native archaeologists, international archaeologists, women...very explicitly my classes compare what the authorship brings to the interpretation of the data and how one person might see things through their particular biases and cultural lens...

Part of this exercise involved encouraging students to reflect on their position in society and how ideas such as access, power, and socialization affect their experiences. Several faculty wanted to help students connect the dots between course content and real life application. These two excerpts show that instructors were prepared to provide students with authentic associations between the information and practical relevance: The first day of my community health class I show them a video about what it means to be a citizen of the world...the global citizen movement...the key thing that comes out of that, the question I always pose is we as human beings should never stop asking "why..."

Part of what I do with my students is to help them understand that they have to understand themselves to be able to understand others...to be able to better serve others and understand themselves and their relationship to society and the social group memberships they're a part of...we start with socialization very early and talking about culture and I have them do a lot of writing and reflecting...sharing within small groups and in large groups... 
Many faculty discussed the value of having students engage in reflective activities to encourage a deeper understanding of cultural matters (Nagaoka, 2016). Oftentimes, faculty said students would be quite surprised at how their views and perspectives changed once they connected the "new to the known."

\section{In-Class Practices: Assessment}

Students must be assessed, and evidence suggests that there must be a high degree of congruence between learning goals (in this case, an exploration and mastery of inclusive principles) and how students are evaluated (Walvoord \& Anderson, 2011). Realizing that the successful attainment of student learning goals is a priority, faculty discussed how they selected and implemented assessment practices that would underscore inclusive practices presented in the course. In a discussion about testing approaches, two psychology faculty members relayed:

One of the things I try to do particularly in my exams or my tests is application based and scenario based...I pull names from various cultures...I've even had students comment "wow these are some crazy names, where did you get them"...but I want them to realize, you know, not everyone looks like you...

One of the essays they can do, for example, is the intersectionality of race, class, sexuality, and gender...some assignments that are tied to that...I try to make my test questions reflect diversity as well as I can...that's sometimes a little bit hard...

Assessment can take many forms and faculty in this study explained how they were willing to allow students latitude in how they demonstrated mastery of course content. Part of establishing inclusive learning environments is realizing that not all students' proof of achievement will be tied to traditional forms of assessment, such as quizzes and objective tests (Gay, 2002). Faculty who wanted to provide students with a diversity of ideas were also prepared to let them exhibit content knowledge in less conventional ways.

\section{Role Modeling and Professional Responsibility}

When reflecting on their tasks as instructors, faculty shared an understanding that they had a responsibility to show students how the content was applicable to their lives but also how students "fit into" the discipline. A number of faculty expressed feeling an obligation to inform students of the state of their profession but also provide a welcoming space for them to feel that they could be a part of the ongoing discussion and change the composition of the discipline. Two professors shared ways that they engage their students in an induction into the state of their profession:

I'm a physics professor, so there are less than two percent of PhDs in physics who are women and even less in other unrepresented groups...so we have a lot of work to do in physics...I try to use science as a platform...I start with scientific papers... a lot of people in physics education have done research to try to see how we can get more of these groups in physics and, based on the data, one of the main things that needs to happen is just discussions about 
underrepresentation...like that was the most powerful thing that someone can do...so I start with that... with papers and show the graphs, show the data, and say "look, we need to talk about getting more people in physics..."

I want the students who are getting degrees in anthropology or archeology or any of the humanities or STEM fields [to know] how does your work matter...why is it relevant...so much of what we do is relevant because it's contributing to these really contentious political things...we basically scrapped half our syllabi last semester in North American Archaeology so we could talk about the Dakota Pipeline which is this really fascinating and evolving intersection of history and sovereignty...heritage and economy and environment...it is just such a wealth of things to discuss and it has a direct relationship to the sorts of jobs my students can expect to get and why they might want to do what they want to do...

Faculty mentioned how facilitating positive and respectful exchanges with students could benefit their interpersonal and intrapersonal growth. Instructors intentionally used class time to give students an opportunity to speak up and voice their concerns or ask questions. Classroom dynamics are predicated on supportive interpersonal exchanges (O'Keeffe, 2013), which faculty accentuated in their courses. Instructors expressed specific techniques they used to enable constructive interactions between students:

As much as possible I try to encourage debate and will ask explicitly divisive questions to get people to try and do that...kind of like the sustained dialogue initiative...trying to communicate with one another more often than not...I sometimes have to play a role and kind of model for students, so that's why I try and bring people in conversation with one another...

I teach religion...nothing controversial there!...and so occasionally if the room seems to have a dominant opinion I try and take a different one..."what about this"...."how would you answer that"... and often I'll say something like "we hear from the extroverts pretty regularly but now I want us all to just be as quiet as long as it takes for some of our more introverted people to have some time to gather their thoughts and participate in the conversation..."

The conversation on culturally relevant andragogy emphasizes how some social groups have been excluded from the conversation for so long, instructors have to be intentional with providing space for students to feel comfortable sharing. Faculty expressed how simply having a warm and caring presence helped them create a learning environment that was productive for all students. They assumed a professional responsibility to show students they belonged in that setting and could thrive while there.

\section{Discussion}

The present study sought to examine how faculty created an inclusive environment in their classroom settings. As is clear in our findings, ideas about 
inclusion are not relegated to the time spent only in the classroom setting but extend to how faculty conceptualize the course and see their role as content experts in helping students of underrepresented groups find a place in the discipline. There is no longer a "typical" college student. In the $21^{\text {st }}$ century, faculty members have to traverse the areas of gender identity, racial demographics, religious ideology, immigration status, and ableness while maintaining a respectful and engaging classroom environment. Faculty discussed ways they actively choose to help students connect with them, the course content, and their peers. Instructors intentionally prepared themselves and students for the inclusive practices they wanted to demonstrate. Whether through syllabus statements or actually expressing it verbally in class, faculty alerted students that the subject area would come up and they would be expected to participate in significant ways. Syllabi can be conceptualized as guides, contracts, and/or collaborative tools (Lund Dean \& Fornaciari, 2014). By placing language in the syllabus about the exploration of diverse perspectives, faculty demonstrated their willingness to open the course to multicultural perspectives.

During class sessions, faculty were deliberate in how they used language to convey an appreciation of diverse opinions and experiences. Faculty made content relevant and relatable to students by presenting examples from different groups and connecting what students were learning to professional goals. Several faculty members emphasized inclusion by consciously choosing to teach students about the contributions of underrepresented groups. Faculty also wanted students to reflect on what they learned to make the course connections deeper. These instructors required students to see the larger implications of the information they were studying.

In terms of assessment, faculty struggled a bit to link inclusive learning goals to evaluate students' mastery of course content. Faculty felt more confident in providing an extensive array of options for students to demonstrate mastery of the course information. Again, instructors offered students the chance to be reflective in their work through debates, service projects, and media assignments. Finally, faculty expressed a sense of professional responsibility to expose students to the larger context within which their discipline operates. Presenting information about underrepresented groups and having discussions to deliberately include less active members of the class were ways faculty tried to increase belongingness amongst the class.

Maslow's theory (1943) provided a model for this study by demonstrating the importance of providing a psychologically safe place for students to maximize learning. As Maslow contended, we are all in the search for an actualized self, and college students are no different. Students should experience a welcoming learning atmosphere in order to thrive to the fullest. Before they can be expected to ascend to a level of mastery and achievement, the environment and the players therein must be willing to provide a psychologically safe place for acquiring the content of the course. Our findings show faculty were able to use tools of collaboration, communication, and active listening to create a sense of community. Faculty were keenly aware that students had to feel connected and engaged for learning to occur (Nagaoka, 2016). They were intentional with their course preparation and instructional practices, encouraging an environment of belongingness and inclusion. 


\section{Limitations and Areas for Future Research}

This study interviewed a small sample of university faculty about their experiences of inclusion in their courses. In the absence of classroom observations or interviews with their students, we cannot be certain that these practices were truly implemented as expressed by the participants (Sciame-Giesecke, Roden, \& Parkison, 2009). Conducting observations of instructional time would be a useful addition to our study to determine the nature of faculty's inclusive teaching practices. It would also be beneficial to speak with students to uncover their perceptions of inclusive learning. The strategies and techniques faculty employ may not have the impact they believe it does. Talking with students about their experiences in courses with a component of multiculturalism would help give some indication of the congruence between student and faculty perspectives. Finally, because some faculty members expressed uncertainty with how to connect diversity learning goals to assessment measures, additional research could explore that practice. Future research could also investigate how, or if, faculty use institutional resources available to them (e.g., teaching grant funds, university-led diversity training) to support their decision to provide an inclusive environment.

\section{Conclusion}

The importance of safe spaces for student learning cannot be denied. College students need inclusive environments that facilitate active participation and a sense of community. Faculty members are the guides in the classroom who help or hinder this process. In this study, we showed how instructors were deliberately reflecting on how to best reach their students and make the classroom setting positive and broadly encompassing of all backgrounds. An instructional triangle presumes students link to their teacher, their peers, and the course content. Faculty who want to develop an inclusive environment are tasked with supporting student connections in all three domains. This study adds to the literature by presenting how a small group of faculty are working to ensure students are better equipped to deal with an ever changing global society.

\section{References}

Bain, K. (2004). What the best college teachers do. Cambridge, MA: Harvard University Press.

Booker, K. C. (2016). Connection and commitment: How sense of belonging and classroom community influence degree persistence for African American undergraduate women. International Journal of Teaching and Learning in Higher Education, 28, 218-229.
Case, K. F. (2013). Teaching strengths, attitudes, and behaviors of professors that contribute to the learning of African-American and Latino/a college students. Journal on Excellence in College Teaching, 24(2), 129-154.

Creswell, J. W., \& Poth, C. N. (2017). Qualitative inquiry $\mathcal{E}$ research design: Choosing among 5 approaches ( $4^{\text {th }}$ ed.). Thousand Oaks, CA: Sage. 
Cuyjet, M., Linden, C., HowardHamilton, M. L., \& Cooper, D. L. (2016). Multiculturalism on campus: Theory, models, and practices for understanding diversity and creating inclusion ( $2^{\text {nd }}$ ed.). Sterling, VA: Stylus.

Finn, J. D., \& Zimmer, K. S. (2012). Student engagement: What is it? Why does it matter? In S. L. Christenson, A. L. Reschly, \& C. Wylie (Eds.), Handbook of research on student engagement (pp. 97131). New York, NY: Springer.

Fredricks, J. A., Blumenfeld, P. C., \& Paris, A. H. (2004). School engagement: Potential of the concept, state of the evidence. Review of Educational Research, 74, 59-109.

doi: 10.3102/00346543074001059

Funge, S. P. (2011). Promoting the social justice orientation of students: The role of the educator. Journal of Social Work Education, 47(1), 73-90.

doi: 10.5175/JSWE.2011.200900035

Gay, G. (2002). Preparing for culturally responsive teaching. Journal of Teacher Education, 53(2), 106-116. doi: 10.1177/0022487102053002003

Goodenow, C. (1993). The Psychological Sense of School Membership among adolescents: Scale development and educational correlates. Psychology in the Schools, 30, 79-90. doi: 10.1002/15206807(199301)30:1<79::AID-PITS23103001 $13>3.0 . \mathrm{CO} ; 2-\mathrm{X}$

Hausmann, L. R., Schofield, J. W., \& Woods, R. L. (2007). Sense of belonging as a predictor of intentions to persist among African American and White first-year college students. Research in Higher Education, 48(7), 803-839.
Hesse, T. (2017, May 25). Appeals court refuses to reinstate Trump's travel ban. The Chronicle of Higher Education. Retrieved from

http://www.chronicle.com/blogs/ticker/ap peals-court-refuses-to-reinstate-trumpstravel-ban/118662?cid $=$ cp90

Johnson, D. R. (2012). Campus racial climate perceptions and overall sense of belonging among racially diverse women in STEM majors. Journal of College Student Development, 53, 336-346.

doi: $10.1353 /$ csd.2012.0028

Kay, D., Summers, J., \& Svinicki, M. (2011). Conceptualizations of classroom community in higher education: Insights from award winning professors. Journal of Ethnographic \& Qualitative Research, 5(4), 230-245.

Kim, Y. K., \& Sax, L. J. (2017). The impact of college students' interactions with faculty: A review of general and conditional effects. In M. B. Paulsen (Ed.), Higher education: Handbook of theory and research (pp. 85-139). Springer International Publishing. doi: 10.1007/978-3-319-48983-4

Lund Dean, K., \& Fornaciari, C. J. (2014). The 21st-century syllabus: Tips for putting andragogy into practice. Journal of Management Education, 38(5), 724-732.

doi: 10.1177/1052562913504764

Maslow, A. H. (1943). A theory of human motivation. Psychological Review, 50(4), 370396. doi: 10.1037/h0054346

McHatton, P. A., Keller, H., Shircliffe, B., \& Zalaquett, C. (2009). Examining efforts to infuse diversity within one college of education. Journal of Diversity in Higher Education, 2(3), 127-135.

doi: $10.1037 / \mathrm{a} 0016190$ 
McMillan, D., \& Chavis, D. (1986). Sense of community: A definition and theory. Journal of Community Psychology, 14, 6-23. doi:

10.1002/1520-6629(198601)14:1<6::AIDJCOP2290140103>3.0.CO;2-I

Morrow, J. A., \& Ackerman, M. E. (2012). Intention to persist and retention of first year students: The importance of motivation and sense of belonging. College Student Journal, 46, 483-491.

doi: 10.1111/hea.12004_7

Murphy, M. C., \& Zirkel, S. (2015). Race and belonging in school: How anticipated and experienced belonging affect choice, persistence, and performance. Teachers College Record, 117(12), 1-40.

Museus, S. D., Yi, V., \& Saelua, N. (2017). The impact of culturally engaging campus environments on sense of belonging. The Review of Higher Education, 40(2), 187-215.

Nagaoka, J. (2016). Foundations for success: Young people learn best through active and reflective experiences. JSD: The Learning Forward Journal. Retrieved from

https://consortium.uchicago.edu/public ations/

Niehaus, E., \& Williams, L. (2016). Faculty transformation in curriculum transformation: The role of faculty development in campus internationalization. Innovative Higher Education, 41(1), 59-74.

doi: 10.1007/s10755-015-9334-7

O'Keeffe, P. (2013). A sense of belonging: Improving student retention. College Student Journal, 47, 605-613. doi: 10.3102/00346543050004545
Onwuegbuzie, A. J., Dickinson, W. B., Leech, N. L., \& Zoran, A. G. (2009). A qualitative framework for collecting and analyzing data in focus group research. International Journal of Qualitative Methods, 8, 1-21.

doi: $10.1177 / 160940690900800301$

Osterman, K. (2000). Students' need for belonging in the school community. Review of Educational Research, 70, 323-367. doi: 10.3102/00346543070003323

Pascarella, E. T., Pierson, C. T., Wolniak, G. C., \& Terenzini, P. T. (2004). Firstgeneration college students: Additional evidence on college experiences and outcomes. Journal of Higher Education, 75(3), 249-284. doi: 10.1353/jhe.2004.0016

Pittman, L. D., \& Richmond, A. (2007). Academic and psychological functioning in late adolescence: The importance of school belonging. The Journal of Experimental Education, 75, 270-290.

doi: 10.3200/JEXE.75.4.270-292

Popovics, A. (2014). Civility on community college campuses: A shared responsibility. College Student Journal, 48(1), 130-132.

Sciame-Giesecke, S., Roden, D., \& Parkison, K. (2009). Infusing diversity into the curriculum: What are faculty members actually doing? Journal of Diversity in Higher Education, 2, 156-165. doi: 10.1037/a0016042

Shochet, I. M., \& Smith, C. L. (2014). A prospective study investigating the links among classroom environment, school connectedness, and depressive symptoms in adolescents. Psychology in the Schools, 51, 480-492. doi: 10.1002/pits.21759 
Sidelinger, R. J., Bolen, D. M., Frisby, B. N., \& McMullen, A. L. (2011). When instructors misbehave: An examination of student-to-student connectedness as a mediator in the college classroom. Communication Education, 60, 340-361. doi: 10.1080/03634523.2011.554991

Strayhorn, T. L. (2012). College students' sense of belonging: A key to educational success for all students. London, England: Routledge.

Thomas, D. R. (2006). A general inductive approach for analyzing qualitative evaluation data. American Journal of Evaluation, 27(2), 237-246.

doi: $10.1177 / 1098214005283748$

Tinto, V. (1993). Leaving college: Rethinking the causes and cures of student attrition ( $2^{\text {nd }}$ ed.). Chicago, IL: University of Chicago Press.

doi: 10.3102/00346543045001089
Walvoord, B. E., \& Anderson, V. J. (2011). Effective grading: A tool for learning and assessment in college ( $2^{\text {nd }}$ ed.) Indianapolis, IN: John Wiley \& Sons. doi: 10.1037/a0030109

Weaver, R. R., \& Qi, J. (2005). Classroom organization and participation: College students' perception. The Journal of Higher Education, 76(5), 570-601.

doi: 10.1080/1463631022000005016

Wilson, S., \& Gore, J. (2013). An attachment model of university connectedness. Journal of Experimental Education, 81, 178-198.

doi: 10.1080/00220973.2012.699902

Zumbrunn, S., McKim, C., Buhs, E., \& Hawley, L. R. (2014). Support, belonging, motivation and engagement in the college classroom: A mixed method study. Instructional Science, 42, 661-684. doi: 10.1007/s11251-014-9310-0

Valentine, K., Prentice, M., Torres, M. F., \& Arellano, E. (2012). The importance of student cross-racial interactions as part of college education: Perceptions of faculty. Journal of Diversity in Higher Education, 5(4), 191-206.

doi: 10.1037/a0030109

Dr. Keonya C. Booker is an Assistant Professor of Psychological Foundations in the Department of Teacher Education at the College of Charleston. Dr. Booker's research agenda involves studying the relationship between school belongingness and academic achievement in African American adolescents.

Dr. Gloria D. Campbell-Whatley is an Associate Professor of Special Education in the College of Education at the University of North Carolina at Charlotte. Dr. Campbell-Whatley's research areas involve diversity training at the postsecondary level and special education administration. 